\title{
DYNAMIC CHARACTERISTICS STUDY ON THE TWO-STAGE SAFETY VALVE USED ON HYDRAULIC SUPPORT UNDER IMPACT LOADING
}

\author{
Guochao Zhao, Hui Wang \\ Liaoning Technical University, School of Mechanical Engineering, Fuxin, China \\ e-mail: wanghui9955@163.com \\ Yuning Song, Changshuai Zhang \\ Yingkou Institute of Technology, Department of Mechanical and Power Engineering, Yingkou, China
}

\begin{abstract}
A two-stage linkage safety valve for hydraulic support is presented. Considering the hydraulic support is impacted, dynamic simulation of the column circuit with the two-stage safety valve subject impact loading was carried out, and the dynamic characteristics of the two-stage safety valve with different impact forms were studied. A rapid impact loading test rig was built to test the two-stage safety valve sample under impact loading. Simulation and experimental results indicate that the two-stage safety valve has high sensitivity and good unloading performance, it can realize fast and large flow unloading of the hydraulic support under different impact forms and pressures.
\end{abstract}

Keywords: safety valve, impact loading, hydraulic support, dynamic characteristic

\section{Introduction}

Hydraulic support, which provides working space for miners and mining equipment by supporting the roof of the coal seam and surrounding rock, is the primary supporting equipment in coal mining face (Zhao et al., 2018). The top beam of hydraulic support in contact with the immediate roof will be subject to higher impact loading when the immediate roof or the main roof is broken. And this is the most common problem which has occurred in China (Wang et al., 2017). An excessive impact load causes serious damage to the hydraulic support, leading to its instability and hydraulic cylinder rupture (Geary, 2013). Once the hydraulic support has problems in the supporting process, it will directly threaten life safety of the miners and the routine operation of the mining equipment, causing enormous economic losses. According to the statistics of coal mining accidents, more than $50 \%$ of the accidents happened due to roof failure (Szurgacz, 2015a). The column is the key component of the hydraulic support in supporting the coal mining face. During supporting of the coal mining face, the column pressure is adjusted by the safety valve of the column circuit and to activate the column lift (Pytlik, 2015). In order to increase the hydraulic support impact resistance against the coal mining face and ensure the coal mining face stability, the column structure and the safety valve in the circuit will be improved (Boutrid et al., 2016).

In recent years, the impact loading of hydraulic support has grown with the increase of mining depth and height. There is an urgent need for the hydraulic support with a large mining height and a large flow safety valve with good dynamic characteristics (Liao et al., 2018).

There were some attractive researches on the safety valve with a large flow. In order to improve the safety of coal mining face, Szurgacz (2015b) carried out 10 numerical simulations and ANSYS CFX simulation of the hydraulic support column under the condition of mine earthquake. The optimum flow rate and column volume under the impact of the roof hydraulic system of the support hydraulic system were finally determined. Szurgacz and Brodny (2018a,b, 2019) 
proposed a DOH hydraulic test system and a free fall load impact test device. The experimental device was used to test the performance of the hydraulic support column. According to the change of the impact height of the load, motion characteristics of the hydraulic support, pressure inside the column and the working efficiency of the safety valve were obtained. The research results provide valuable data and experimental reference for the research of hydraulic support under dynamic loading conditions. Brodny $(2010,2011)$ carried out theoretical research and experimental tests on the change of the transmission force of the friction joint of the hydraulic support under dynamic load impact. Through the standard test and digital simulation, the working characteristics and yielding ability of the friction joint under axial impact were obtained. The developed friction joint model and the experimental bench are of great significance for parameter matching of the hydraulic support and optimization of the friction joint under dynamic loading. Liao et al. (2015a) analyzed the stress situation of a high water-based electro-hydraulic proportional directional valve under multiple factors affected by AMESim and ANSYS/LS-DYNA. Liao et al. (2015b) studied the radial unbalance force of a single-channel valve by using CFD, and a double-channel model was designed to improve it. Xu et al. (2014) designed a high flow capacity and fast response directional control valve with a three-stage structure, and its dynamic characteristics were studied by simulation and experimental methods. Posa et al. (2013) studied the flow coefficient and flow force of a directional hydraulic valve with different openings and pressure drop with an immersed-boundary method. Gao et al. (2013) and Yang et al. (2017) analyzed factors affecting the flow force of a large flow directional control valve by using numerical simulation and tests. Amirante et al. (2016), Lisowski and Filo (2016), Lisowski et al. (2018) and Liu et al. (2015) designed shape of the valve port to satisfy the requirement of high pressure and the large flow of a proportional valve. Lei et al. (2018), He et al. (2013) and Zhang et al. (2011) analyzed the influence of different structural parameters on the pressure and flow dynamic characteristics of a high pressure and large flow safety valve. Dai et al. (2018) analyzed the effects of the inlet flow rate, working pressure and diameter of the damping hole and spring stiffness on the response characteristics of the safety valve by a combination of simulation and experiment. Zhao and Liu (2018) studied vibration and cavitation characteristics of the safety valve under reversing impact conditions, and improved violent vibration of the safety valve when the pressure changes were optimized by the valve cone angle.

Many studies have addressed factors affecting the performance of high pressure and large flow safety valves. But in the present situation of coal mining, the main function of the high pressure and large flow safety valve is to unload the hydraulic support when the impact load is generated. It is essential to study dynamic characteristics of safety valve under impact load for structural evolution design of the large flow safety valve. In this paper, the two-stage safety valve, which is a combination of a direct relief valve and differential cone valve, is presented. And a mathematical model of the column circuit with the two-stage safety valve opening and closing process is established. On this basis, we studied the effect of different roof impact forms on dynamic characteristics of the two-stage safety valve. In addition, a rapid impact loading test rig was built to test the two-stage safety valve sample under different impact pressure.

\section{Structure of two-stage safety valve}

As shown in Fig. 1, the two-stage safety valve consists of a direct relief valve and a differential cone valve. The rated flow and rated pressure of two-stage safety valve is $1000 \mathrm{~L} / \mathrm{min}$ and $60 \mathrm{MPa}$, respectively. The rated flow of the direct relief valve is $Q_{1}=50 \mathrm{~L} / \mathrm{min}$ and the rated pressure is $P_{1}=45 \mathrm{MPa}$. When the pressure fluctuation amplitude of the column circuit is small, a certain amount of emulsion is discharged through the direct relief valve, which stabilizes the column circuit pressure. Due to the limitation of its structure, the flow of the direct relief valve is small, 
and the opening pressure is low. The rated flow of the differential cone valve is $Q_{2}=1000 \mathrm{~L} / \mathrm{min}$ and the rated pressure is $P_{2}=50 \mathrm{MPa}$. When the column circuit generates large pressure fluctuations because of the roof impact, a large amount of high-pressure emulsion is discharged from the differential cone valve to protect the column circuit, and the two-stage safety valve has a good unloading performance under different impact forms and pressures.
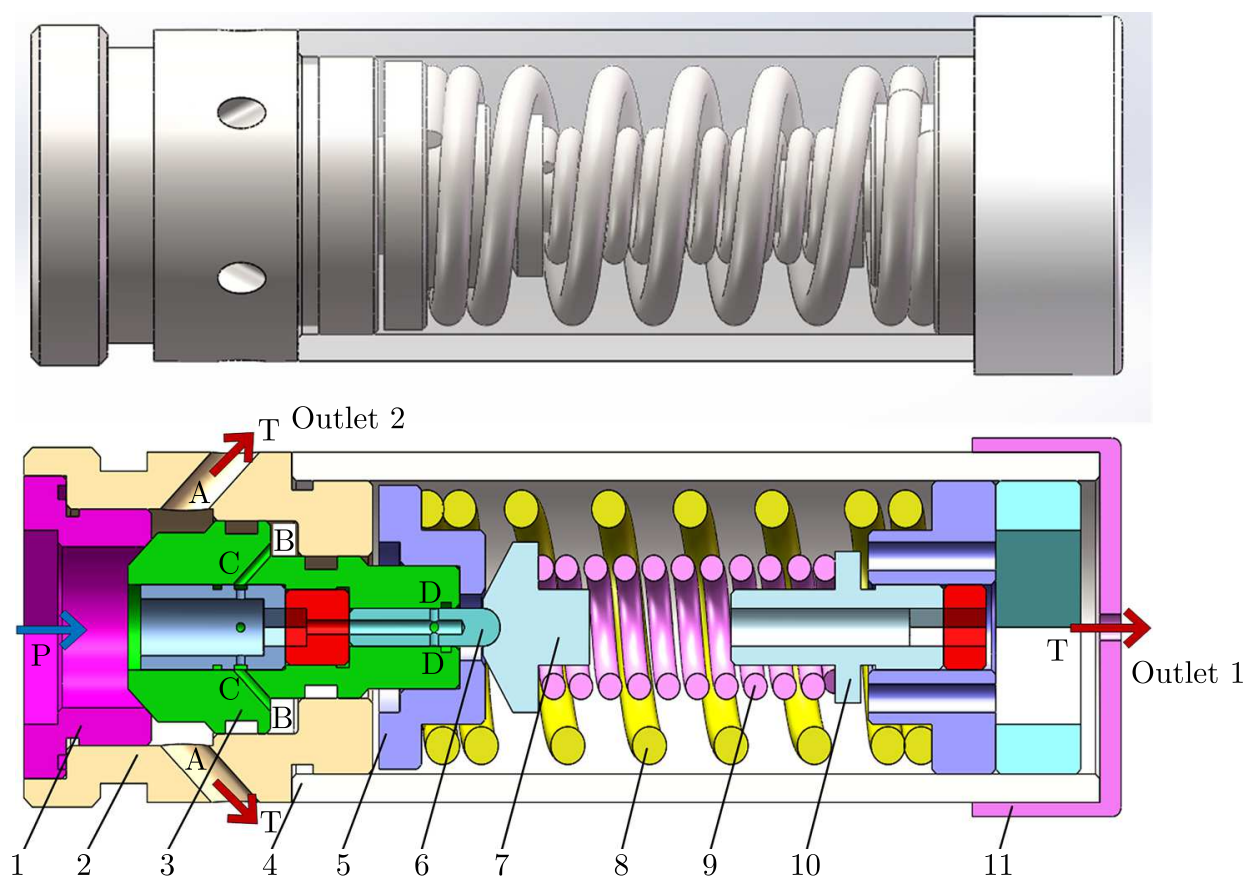

Fig. 1. Structure of the two-stage safety valve: 1 - connector, 2 - seat, 3 - differential cone valve, 4 - pocket, 5 - outer spring seat, 6 - direct relief valve, 7 - inner spring seat, 8 - outer spring, 9 - inner spring, 10 - spring adjustment screw, 11 - dust cup

The working process of the two-stage safety valve can be described as follows: when the hydraulic support top beam is subjected to impact, the pressure of the lower cavity of the column circuit increases rapidly, which pushes the emulsion in the column into the valve cavity of the safety valve. The high-pressure emulsion enters the differential cone valve through the damper port $C$ on the valve core and acts on the differential pressure area $B$. In addition, a part of the emulsion acts on the direct relief valve through the valve core cavity. When the pressure of the lower cavity of the column circuit increases to the opening pressure of the direct relief valve, the direct relief valve opens and the emulsion in the valve flows from the jet port in the dust cup, so that the pressure of the lower cavity of the column circuit is initially controlled. When the roof subsidence speed is increased and generates a large impact loading, the pressure of the lower cavity of the column circuit increases rapidly. It is necessary to discharge a large amount of high-pressure emulsion in the lower cavity quickly and protect the column circuit through unloading. However, the rated flow of the direct relief valve is too small to unload, even when the valve is fully opened. In this case, the differential cone valve opens and achieves rapid unloading of the column circuit, as the high-pressure emulsion flows through the outlet $A$. Finally, the stability of hydraulic support is increased.

According to the rated flow and rated pressure of the two-stage safety valve, the mathematical model of the two-stage safety valve can be expressed as follows

$$
Q_{s 1}=\frac{d P_{s}}{d t} \frac{V_{s 1}}{\beta}+Q_{1}+A_{1} \frac{d x_{1}}{d t}
$$


where $Q_{s 1}$ is the inlet flow of the two-stage valve $[\mathrm{L} / \mathrm{min}] ; P_{s}$ is the inlet pressure [MPa]; $\beta$ is the bulk elastic modulus of emulsion $\left[\mathrm{N} / \mathrm{m}^{2}\right] ; A_{1}$ is the area of fluid inlet for the direct relief valve $\left[\mathrm{m}^{2}\right]$ and $V_{s 1}$ is the volume of the emulsion in the direct relief valve $\left[\mathrm{m}^{3}\right]$.

The outlet flow equation of the direct relief valve is

$$
Q_{1}=C_{d} W x_{1} \sin \alpha \sqrt{\frac{2}{\rho}\left(P_{s}-P_{o}\right)}
$$

where $Q_{1}$ is the outlet flow rate of the direct relief valve $[\mathrm{L} / \mathrm{min}] ; W$ is the wetted perimeter $[\mathrm{m}]$; $C_{d}$ is the flow coefficient of the direct relief valve; $x_{1}$ is the displacement of the direct relief valve $[\mathrm{m}] ; P_{o}$ is the outlet pressure, and $\rho$ is density of the emulsion $\left[\mathrm{kg} / \mathrm{m}^{3}\right]$.

The dynamic equation of the direct relief valve is

$$
m_{1} \frac{d x_{1}^{2}}{d^{2} t}+B \frac{d x_{1}}{d t}=P_{s} A_{1}-K_{t 1}\left(L_{1}+x_{1}\right)-K_{s} P_{s} x_{1}
$$

where $m_{1}$ is mass of the direct relief valve [kg]; $B$ is the equivalent damping coefficient $[\mathrm{Ns} / \mathrm{m}]$; $K_{t 1}$ is stiffness of the inner spring $[\mathrm{N} / \mathrm{m}] ; L_{1}$ is the initial compression quantity of the inner spring $[\mathrm{m}]$; and $K_{s}$ is the stiffness coefficients of the flow force $[\mathrm{N} / \mathrm{m}]$.

The inlet flow equation of the differential cone valve is

$$
Q_{s 2}=\frac{d P_{s}}{d t} \frac{V_{s 2}}{\beta}+Q_{2}+A_{2} \frac{d x_{2}}{d t}
$$

where $A_{2}$ is the area of fluid inlet for the differential cone valve $\left[\mathrm{m}^{2}\right.$; and $V_{s 2}$ is volume of the emulsion in the differential cone valve $\left[\mathrm{m}^{3}\right]$.

The outlet flow equation of the differential cone valve is

$$
Q_{2}=C_{d} W x_{2} \sin \alpha \sqrt{\frac{2}{\rho}\left(P_{s}-P_{o}\right)}
$$

Because the structure of the differential cone valve and the direct relief valve are different, the differential cone valve is subjected to the radial hydraulic force $P_{s} \Delta A$ which is generated by the annular differential area. The dynamic equation of the differential cone valve is

$$
m_{2} \frac{d x_{2}^{2}}{d^{2} t}+B \frac{d x_{2}}{d t}+P_{s} \Delta A=P_{s} A_{2}-K_{t 2}\left(L_{2}+x_{2}\right)-K_{s} P_{s} x_{2}
$$

where $m_{2}$ is mass of the differential cone valve [kg]; $\Delta A$ is differential area [m]; $K_{t 2}$ is stiffness of the outer spring $[\mathrm{N} / \mathrm{m}] ; L_{2}$ is the initial compression quantity of the outer spring $[\mathrm{m}]$.

\section{Model of the column circuit of hydraulic support with the two-stage safety valve}

The structure of working face support is shown in Fig. 2. The hydraulic support is often subjected to the impact loading caused by fracture and slump of the coal seam roof (Verma, 2013). There are two main types of impact loading: loading generated when immediate roof cracks and breaks, and impact loading generated by unbalanced pressure of the main roof occuring when the mining depth is increased (Zeng et al., 2018b).

The transfer rule of the impact loading on the hydraulic support can be described as follows: the impact loading on the hydraulic support is transmitted from the coal seam roof (main roof or immediate roof) through the column circuit to the hydraulic support safety valve. Through this transfer, the impact loading is converted into a pressure change of the emulsion in the column 


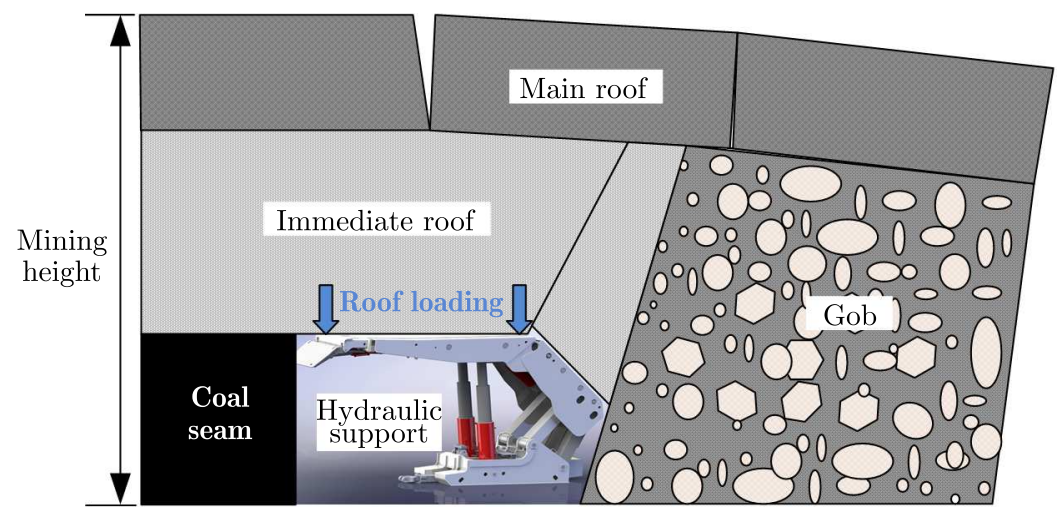

Fig. 2. Structure of working face support

circuit. Eventually, a large amount of the high-pressure emulsion is discharged from the safety valve, and the generated impact loading is unloaded.

When the coal seam roof is broken or unbalanced, the immediate roof sinks rapidly. Then the hydraulic support is subjected to a powerful impact loading. And the pressure and volume of the column circuit change. In this condition, the hydraulic support can only be protected by a continuous and rapid unloading through the safety valve in the column circuit. Because the impact loading requires transient flow accumulation and transmits from the hydraulic support top beam to the column in a short time, the change of column piston cavity pressure and volume will lead to compression of the emulsion and expansion and deformation of the material of the column cylinder. Therefore, the drop height of the immediate roof is determined by volume of the gob, and thickness of the immediate roof can be calculated as follows

$$
h=\frac{H}{K_{0}-1}
$$

where $h$ is thickness of the immediate roof [m]; $H$ is mining height [m]; $K_{0}$ is the loose coefficient of rock.

The weight of the immediate roof is

$$
G=a b h \gamma=a b \frac{H}{K_{0}-1} \gamma
$$

where $a$ is length of the hydraulic support top beam $[\mathrm{m}] ; b$ is width of the hydraulic support top beam $[\mathrm{m}] ; \gamma$ is volumetric weight $\left[\mathrm{N} / \mathrm{m}^{3}\right]$.

The impact loading of the roof on the hydraulic support can be equivalent to the product of weight of the immediate roof and the impact load coefficient. So the maximum impact loading on hydraulic supports is

$$
F_{\max }=\eta G=\eta a b \frac{H}{K_{0}-1} \gamma
$$

The impact loading coefficient $\eta$ is related to the mining height (Zeng et al., 2018a). In this paper, set $\eta$ as 2 and $K_{0}$ as 1.5, the maximum impact loading on hydraulic supports can be expressed as follows

$$
F_{\max }=4 a b H \gamma
$$

Figure 3 shows the structure of the hydraulic support column circuit with the two-stage safety valve. As the impact loading on the top beam of hydraulic support is cyclic, different impact forms of the roof directly affect the relationship between the column piston and cavity 
pressure. The column circuit regulates and controls the column piston cavity pressure through opening and closing of the safety valve. Therefore, the pressure and flow characteristics of the safety valve can reflect the change rule of the column piston cavity pressure.

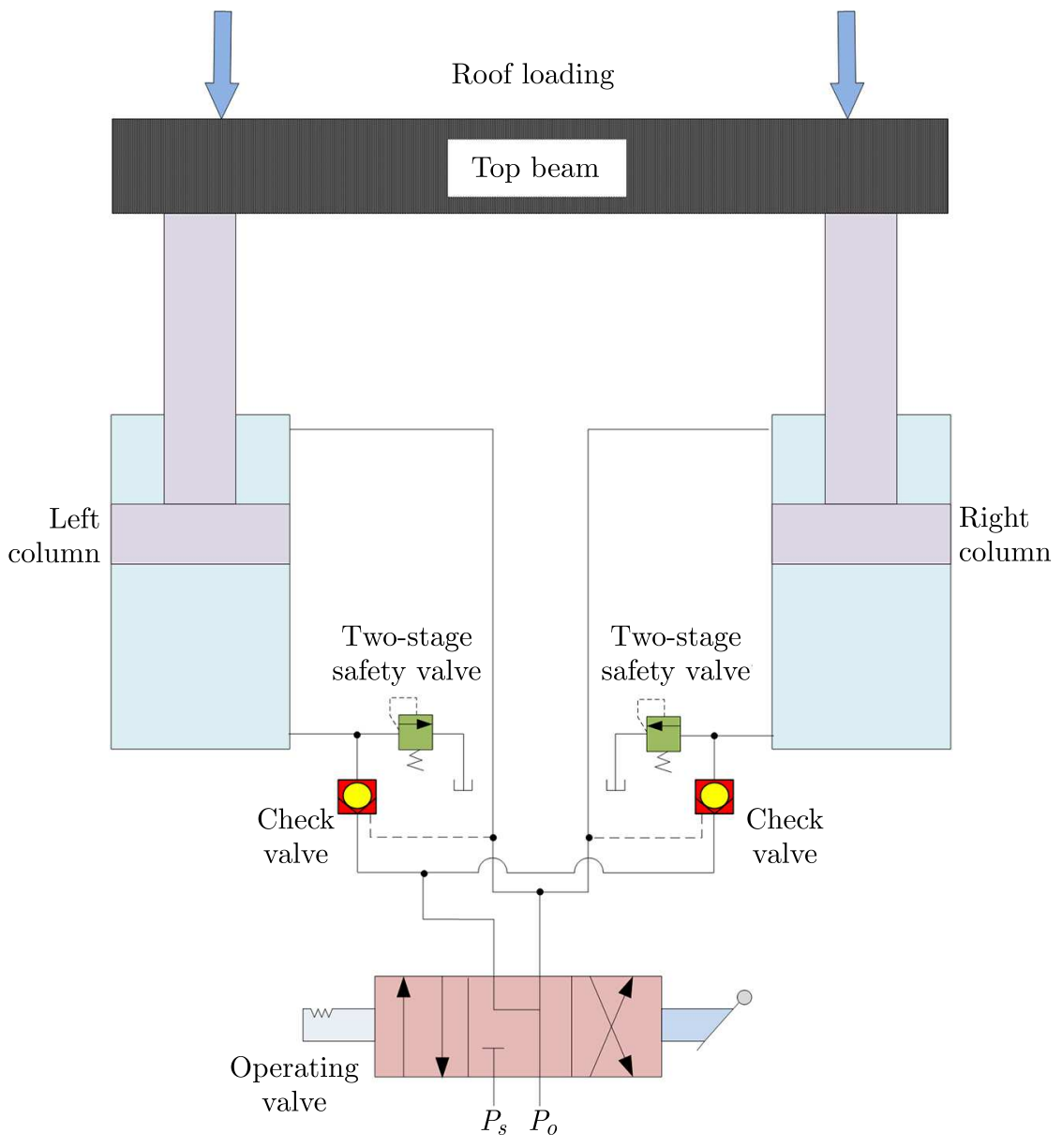

Fig. 3. Structure of the column circuit of hydraulic support

The roof beam sinks because of suffering impact loading. And then the column piston cavity pressure increases. The valve opens and depressurizes the pressure of the hydraulic support column. As the high-pressure emulsion is discharged, the pressure in the column piston cavity is released and the valve is closed to maintain the pressure balance of the column.

Under the roof impact loading, the flow equation of the column circuit can be expressed as follows

$$
A_{s} v-\frac{V}{\beta} \frac{d P}{d t}=C_{d} \pi d x \sqrt{\frac{2 \Delta P}{\rho}}+A_{2} \frac{d x}{d t}
$$

where $A_{s}$ is area of the bottom surface of the column piston, $\left[\mathrm{m}^{2}\right] ; v$ is speed of the roof impact $[\mathrm{m} / \mathrm{s}] ; V$ is volume of the column piston cavity $\left[\mathrm{m}^{3}\right]$.

The column is rigidly deformed when the roof is impacted. And the volume of the column piston cavity changes. The column can be regarded as a thin-walled cylinder as the wall thickness of the column is much smaller than the diameter of the column. Therefore, the volume change equation of the piston cavity of the column can be expressed as follows

$$
V=\pi\left(D_{1}+\Delta D_{1}\right)^{2}\left(l_{0}-l\right) \quad \Delta D_{1}=\frac{D_{1}^{2}}{2 E}\left(\frac{D_{1}^{2}+D_{2}^{2}}{D_{2}^{2}-D_{1}^{2}}+\mu\right) P_{s}
$$


where $E$ is the elastic modulus of the column material $\left[\mathrm{N} / \mathrm{m}^{2}\right] ; \mu$ is the Poisson ratio of the column material; $l_{0}$ is the initial height of the column piston $[\mathrm{m}] ; l$ is the final height of the column piston $[\mathrm{m}] ; D_{1}$ is the inner diameter of the column $[\mathrm{m}] ; D_{2}$ is the outer diameter of the column $[\mathrm{m}] ; \Delta D_{1}$ is the deformation of the inner diameter of the column [m].

The dynamic equation of the column circuit in this process can be expressed as follows

$$
\begin{aligned}
& m_{2} \frac{d x_{2}^{2}}{d^{2} t}+B \frac{d x_{2}}{d t}+P_{s} \Delta A=P_{s} A_{2}-K_{t 2}\left(L_{2}+x_{2}\right)-K_{s} P_{s} x_{2} \frac{V_{s}}{\beta} \frac{d P}{d t} \\
& \quad=\left\{A_{s} v-C_{d} \pi d x \sqrt{\frac{2 \Delta P}{\rho}}-A_{2} \frac{d x}{d t}\right. \\
& \left.\quad-\frac{1}{E}\left[\pi\left(D_{1}+\frac{D_{1}^{2}}{2 E}\left(\frac{D_{1}^{2}+D_{2}^{2}}{D_{2}^{2}-D_{1}^{2}}+\mu\right) P_{s}\right)^{2}\left(l_{0}-l_{1}\right)\right] \frac{d P}{d t}\right\} A_{s} v \\
& -\frac{1}{E}\left[\pi\left(D_{1}+\frac{D_{1}^{2}}{2 E}\left(\frac{D_{1}^{2}+D_{2}^{2}}{D_{2}^{2}-D_{1}^{2}}+\mu\right) P_{s}\right)^{2}\left(l_{0}-l_{1}\right)\right] \frac{d P}{d t} \\
& \left.\frac{d l}{d t}\right|_{t=0}=\left.0 \quad \frac{d x_{2}}{d t}\right|_{t=0}=0
\end{aligned}
$$

\section{Dynamic characteristics of the two-stage safety valve under impact loading}

According to dynamic equation (3.7), dynamic characteristics of the two-stage safety valve under two different impact forms of the roof are simulated by using Matlab/Simulink.

Figure 4 shows dynamic characteristics of the two-stage safety valve for a single simulated impact. The simulated impact form is a triangular shock signal with a constant impact duration and different impact speeds. In this paper, the impact duration is determined as $0.10 \mathrm{~s}-0.50 \mathrm{~s}$, and the impact speeds are $0.26 \mathrm{~m} / \mathrm{s}, 0.41 \dot{\mathrm{m}} / \mathrm{s}, 0.53 \mathrm{~m} / \mathrm{s}, 0.64 \mathrm{~m} / \mathrm{s}, 0.80 \mathrm{~m} / \mathrm{s}$. As shown in Fig. 4 ,
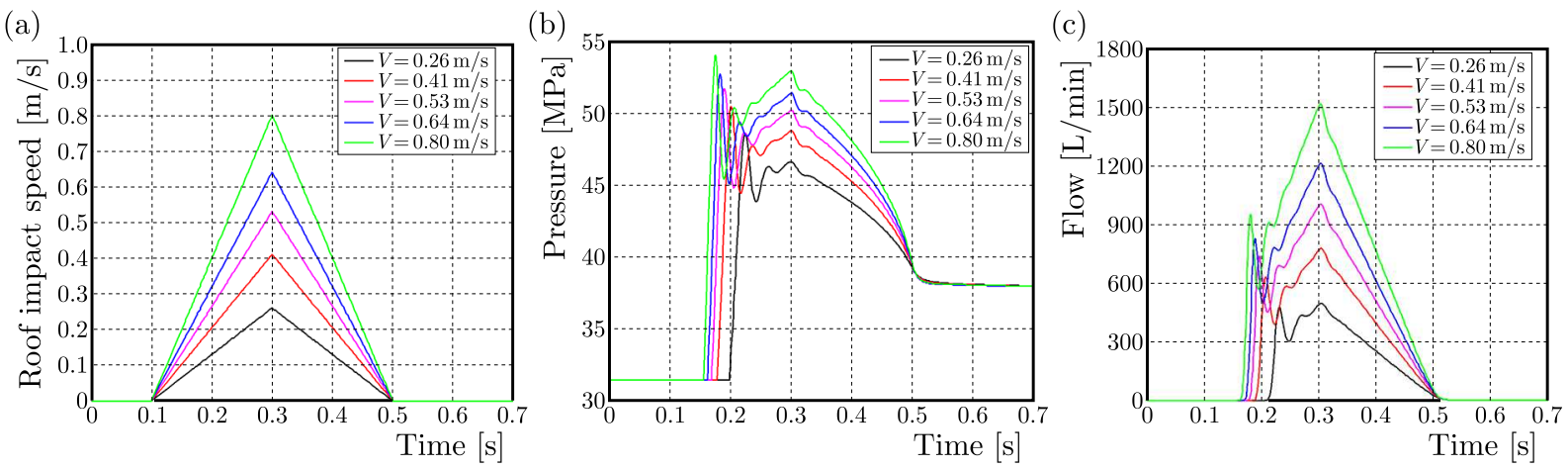

Fig. 4. Simulation results for different impact speeds: (a) roof impact speed, (b) pressure of the two-stage safety valve, (c) flow of the two-stage safety valve

the roof impact speed is increased, the rise time of safety valve pressure and flow is decreased, and nonlinear oscillation occurs. A large amount of the high-pressure emulsion is discharged through the safety valve at $0.17 \mathrm{~s}-0.31 \mathrm{~s}$, and the pressure and flow of the safety valve fluctuates greatly with the increase of the roof impact speed. When the roof impact speed is $0.26 \mathrm{~m} / \mathrm{s}$, the pressure ranges from $44 \mathrm{MPa}$ to $48 \mathrm{MPa}$, and the flow ranges from $300 \mathrm{~L} / \mathrm{min}$ to $500 \mathrm{~L} / \mathrm{min}$. When the roof impact speed is $0.41 \mathrm{~m} / \mathrm{s}$, the pressure ranges from $44.8 \mathrm{MPa}$ to $50.5 \mathrm{MPa}$, and the flow ranges from $400 \mathrm{~L} / \mathrm{min}$ to $750 \mathrm{~L} / \mathrm{min}$. When the roof impact speed is $0.53 \mathrm{~m} / \mathrm{s}$, the pressure ranges from $44.9 \mathrm{MPa}$ to $52 \mathrm{MPa}$, and the flow ranges from $460 \mathrm{~L} / \mathrm{min}$ to $1000 \mathrm{~L} / \mathrm{min}$. When the roof impact speed is $0.64 \mathrm{~m} / \mathrm{s}$, the pressure ranges from $45 \mathrm{MPa}$ to $53 \mathrm{MPa}$, and the flow ranges 
from $500 \mathrm{~L} / \mathrm{min}$ to $1210 \mathrm{~L} / \mathrm{min}$. When the roof impact speed is $0.80 \mathrm{~m} / \mathrm{s}$, the pressure ranges from $44 \mathrm{MPa}$ to $48 \mathrm{MPa}$, and the flow ranges from $590 \mathrm{~L} / \mathrm{min}$ to $1510 \mathrm{~L} / \mathrm{min}$. After $0.31 \mathrm{~s}$, the roof impact speed is reduced, the pressure in the column tends to be stable, and the safety valve is gradually closed to maintain the pressure of the column. Finally, the pressure of the safety valve is maintained in the vicinity of $38 \mathrm{MPa}$.

Figure 5 shows the two-stage safety valve dynamic characteristics for another simulated impact. The simulated impact form is a triangular shock signal with a constant impact speed and different impact durations. In this paper, impact speed is $0.53 \mathrm{~m} / \mathrm{s}$, and the impact duration is $0.04 \mathrm{~s}-0.56 \mathrm{~s}, 0.07 \mathrm{~s}-0.53 \mathrm{~s}, 0.10 \mathrm{~s}-0.50 \mathrm{~s}, 0.13 \mathrm{~s}-0.47 \mathrm{~s}, 0.16 \mathrm{~s}-0.44 \mathrm{~s}$. As shown in Fig. 6, the roof impact duration is decreased, the rise time of safety valve pressure and flow is invariant, and the peak of fluctuation is gradually increased. When the roof impact duration is $0.04 \mathrm{~s}-0.56 \mathrm{~s}$, the pressure fluctuation ranges from $44.5 \mathrm{MPa}$ to $50.5 \mathrm{MPa}$, and the flow fluctuation ranges from $390 \mathrm{~L} / \mathrm{min}$ to $630 \mathrm{~L} / \mathrm{min}$. When the roof impact duration is $0.07 \mathrm{~s}-0.53 \mathrm{~s}$, the pressure fluctuation ranges from $44.6 \mathrm{MPa}$ to $51 \mathrm{MPa}$, and the flow fluctuation ranges from $410 \mathrm{~L} / \mathrm{min}$ to $680 \mathrm{~L} / \mathrm{min}$. When the roof impact duration is $0.10 \mathrm{~s}-0.50 \mathrm{~s}$, the pressure fluctuation ranges from $44.7 \mathrm{MPa}$ to $51.8 \mathrm{MPa}$, and the flow fluctuation ranges from $450 \mathrm{~L} / \mathrm{min}$ to $740 \mathrm{~L} / \mathrm{min}$. When the roof impact duration is $0.13 \mathrm{~s}-0.47 \mathrm{~s}$, the pressure fluctuation ranges from $45 \mathrm{MPa}$ to $52.6 \mathrm{MPa}$, and the flow fluctuation ranges from $490 \mathrm{~L} / \mathrm{min}$ to $810 \mathrm{~L} / \mathrm{min}$. When the roof impact duration is $0.16 \mathrm{~s}-0.44 \mathrm{~s}$, the pressure fluctuation ranges from 45.3 MPa to $53.6 \mathrm{MPa}$, and the flow fluctuation ranges from $540 \mathrm{~L} / \mathrm{min}$ to $950 \mathrm{~L} / \mathrm{min}$. Finally, the pressure of the safety valve is remained in the vicinity of $38 \mathrm{MPa}$ when the roof impact speed disappears.

(a)

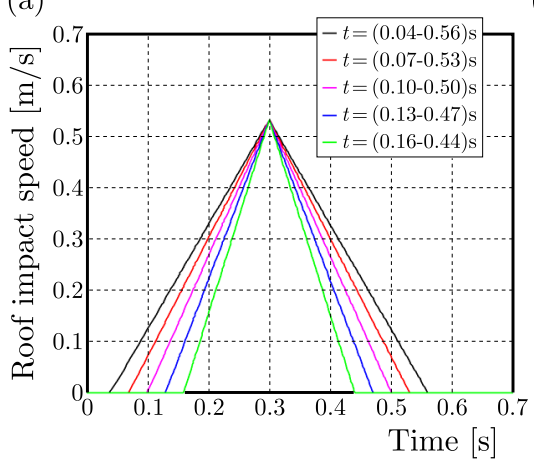

(b)

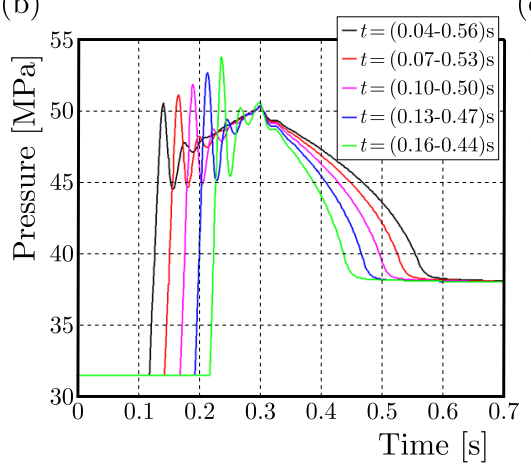

(c)

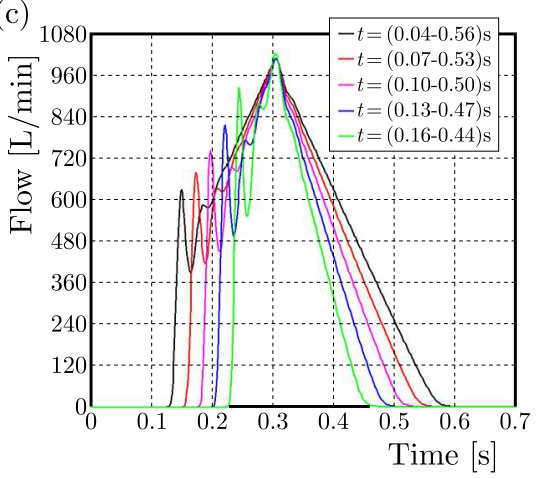

Fig. 5. Simulation results for different impact durations: (a) roof impact speed, (b) pressure of the two-stage safety valve, (c) flow of the two-stage safety valve

\section{Experimental research}

In order to evaluate dynamic characteristics of the two-stage safety valve under impact loading, a fast loading impact test rig was built as shown in Fig. 6 .

The hydraulic circuit structure of the test rig is an impact test system using an accumulator as a power source. The accumulator needs to be continuously filled by a gear pump (the working medium is an emulsion) before the start of the test, so that pressure in the accumulator can reach the pressure required for the experiment. In the impact experiment, the accumulator releases a large amount of the high pressure emulsion as the source of impact, and the process of unloading is simulated. This impact loading system is not only simple in structure, but also has high operability, and the impact loading process is fast.

A photograph of the fast loading impact test rig and the two-stage safety valve are shown in Fig. 7. The experimental tests are carried out in three pressure conditions, $56 \mathrm{MPa}, 57 \mathrm{MPa}$, and $58 \mathrm{MPa}$. In the experiment, a safety cover is used to protect the two-stage safety valve 


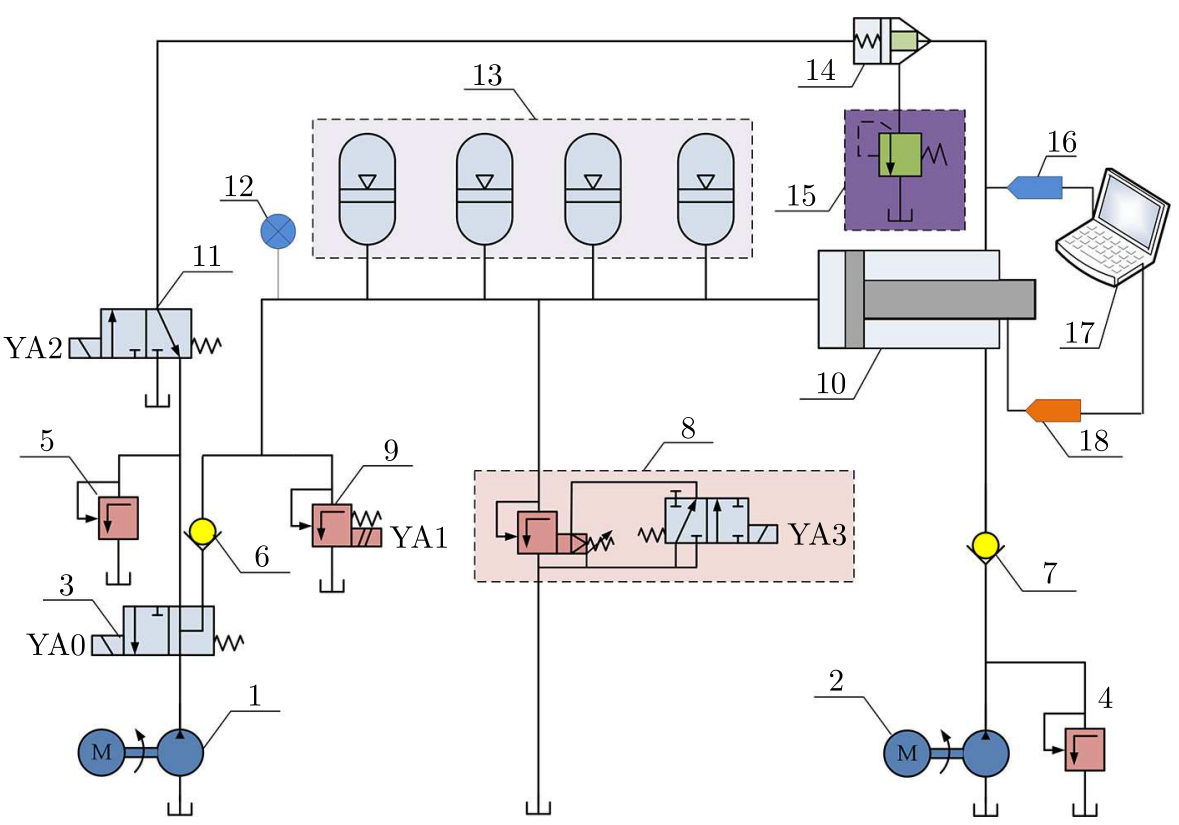

Fig. 6. The elements of the test rig: 1 - oil pump, 2 - emulsion pump, 3 - directional valve, 4 and 5 - relief valve, 6 and 7 - check valve, 8 - unloading valve, 9 - proportional relief valve, 10 - pressurized cylinder, 11 - on-off valve, 12 - pressure gauge, 13 - accumulator, 14 - cartridge valve, 15 - two-stage safety valve, 16 - pressure sensor, 17 - data acquisition computer, 18 - displacement sensor

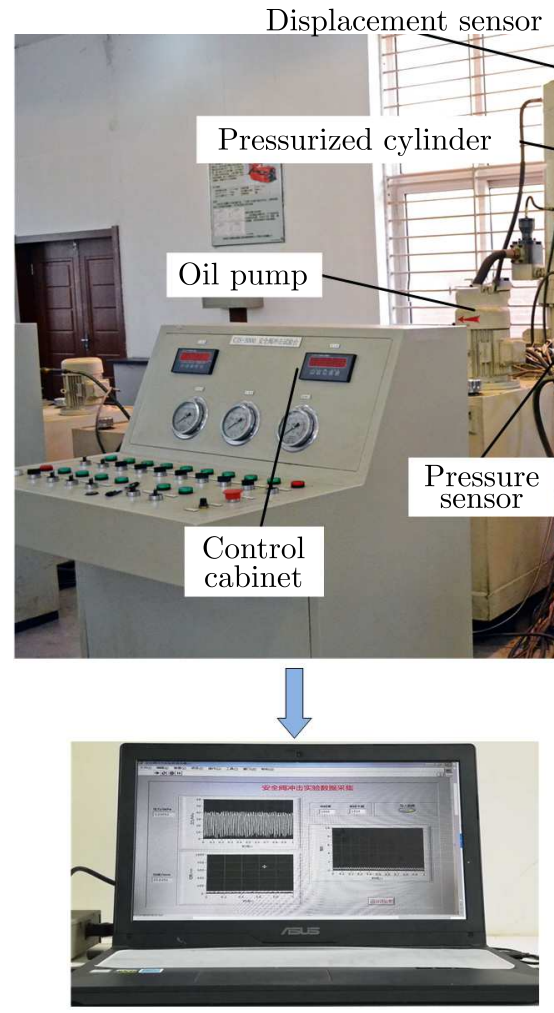

Data acquisition computer
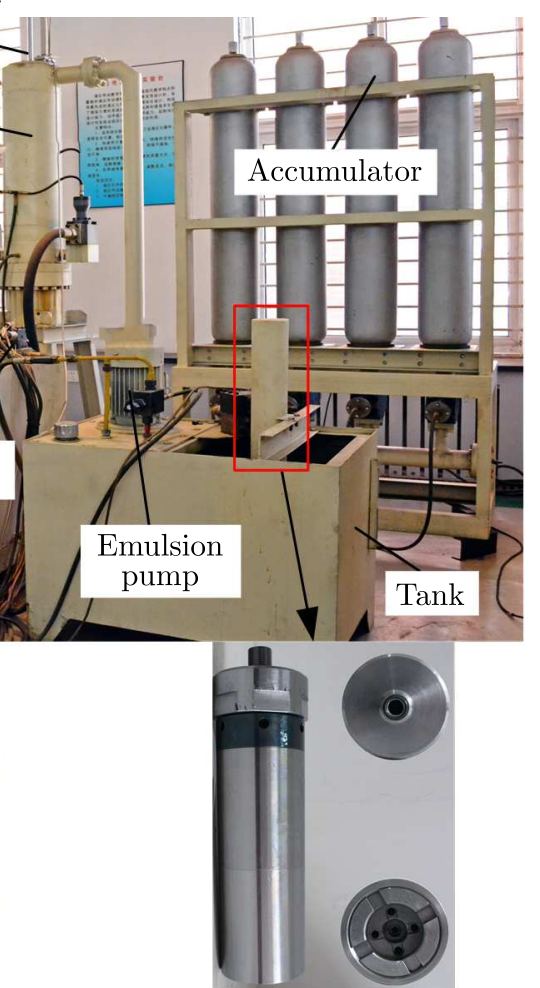

Two-stage safety valve

Fig. 7. The experimental setup 
against emulsion spatter. It is important to note that the impact test can not be carried out until pressure of the accumulator reaches the set value, it takes a certain amount of time to complete the filling of the accumulator before loading. Therefore, two tests were performed for individual pressure values within three days.

Figure 8a shows pressure characteristics of the two-stage safety valve under three impact pressure conditions. The impact starts at $10.39 \mathrm{~s}$, and the pressure of the two-stage safety valve increases rapidly to reach the set value of the impact pressure. Then, the valve opens and overflows, so that the internal pressure of the valve decreases. After repeated fluctuations, the final pressure of the valve is about $45 \mathrm{MPa}$. After the high-pressure emulsion is discharged, the safety valve is closed to maintain the pressure of the system at the final value of $32 \mathrm{MPa}$. When the impact pressure is $58 \mathrm{MPa}$, the pressure overshoot $\Delta P$ is $28.8 \%$. When the impact pressure is $57 \mathrm{MPa}$, the pressure overshoot $\Delta P$ is $26.6 \%$. When the impact pressure is $56 \mathrm{MPa}$, the pressure overshoot $\Delta P$ is $24.4 \%$. The pressure rise time $t_{1}$ is $20 \mathrm{~ms}$ and the pressure stable time $t_{2}$ is $40 \mathrm{~ms}$.

As shown in Fig. 8b, beginning at $10.39 \mathrm{~s}$, the time of impact starts and the two-stage safety valve opens repeatedly to unload with flow fluctuation. The flow fluctuation is more intense within $10 \mathrm{~ms}$ after the impact starts. The bigger is the impact pressure, the more violent fluctuation is. When the impact pressure is $56 \mathrm{MPa}$, the flow fluctuation ranges from $847 \mathrm{~L} / \mathrm{min}$ to $1174 \mathrm{~L} / \mathrm{min}$. When the impact pressure is $57 \mathrm{MPa}$, the flow fluctuation ranges from $713 \mathrm{~L} / \mathrm{min}$ to $1207 \mathrm{~L} / \mathrm{min}$. When the impact pressure is $58 \mathrm{MPa}$, the flow fluctuation ranges from $843 \mathrm{~L} / \mathrm{min}$ to $1251 \mathrm{~L} / \mathrm{min}$. After $10 \mathrm{~ms}$, the safety valve is in a stable unloading state and the flow fluctuation is obviously reduced, maintained at about $950 \mathrm{~L} / \mathrm{min}$.

(a)

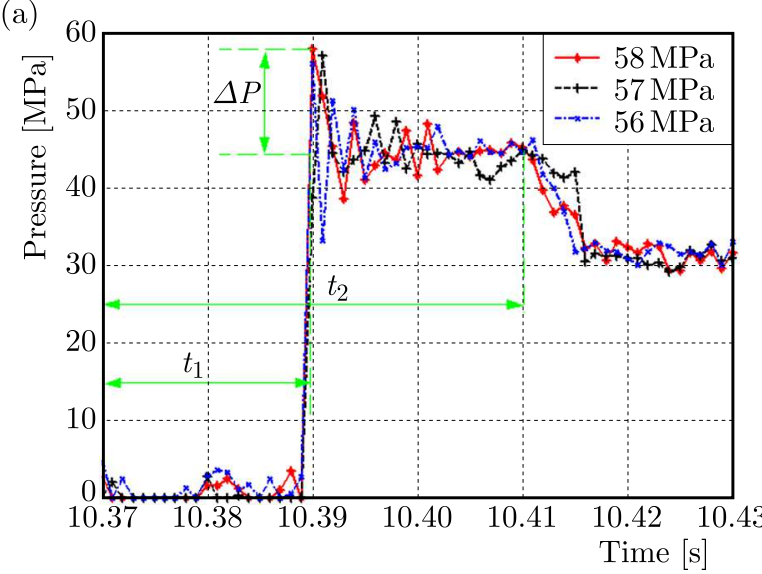

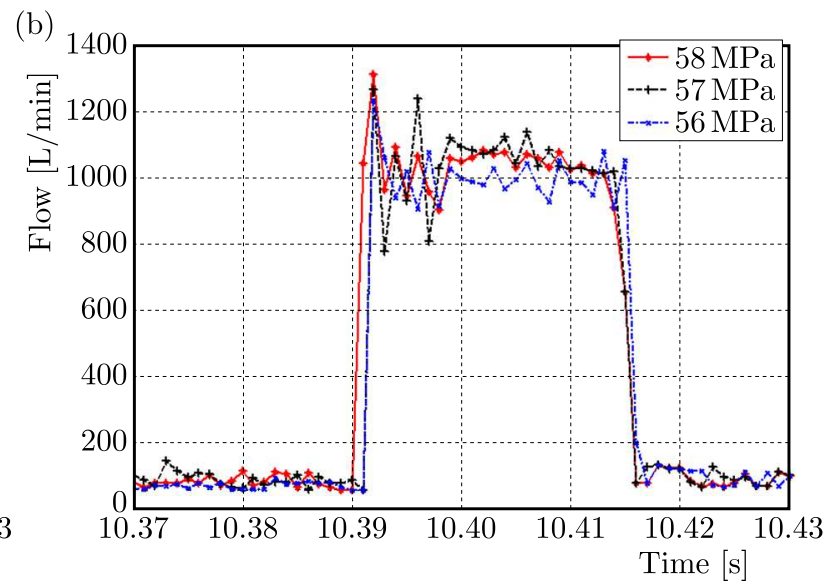

Fig. 8. Test results: (a) pressure of the two-stage safety valve, (b) flow of the two-stage safety valve

Statistical analysis of the experimental results (shown as Fig. 8) shows that the impact pressure is increased from $56 \mathrm{MPa}$ to $58 \mathrm{MPa}$, pressure overshoot $\Delta P$ is increased by $4.4 \%$, pressure rise time $t_{1}$ and pressure stabilization time $t_{2}$ are almost unchanged. From the waveform diagram obtained by the experiment, it can be seen that from $10.39 \mathrm{~s}$ to $10.41 \mathrm{~s}$, the internal pressure and flow of the two-stage safety valve fluctuate repeatedly, and the degree of fluctuation increases with the increase of the impact pressure. This phenomenon indicates that under conditions of pressure impact loading, the spool of the two-stage safety valve reciprocating motion causes a change in the opening amount, a certain pressure and flow of liquid is discharged until the pressure is stabilized within the rated pressure range of the valve. There are some slight fluctuations in the experimental results at $1037 \mathrm{~s}-10.39 \mathrm{~s}$ and $10.41 \mathrm{~s}-10.43 \mathrm{~s}$, since high pressure impact reduces valve sealing performance and leads to certain leakage problems. However, this kind of problem has little effect on the whole experimental result and can be ignored.

According to the experimental results, when subjected to impact loading, the safety valve can unload the high pressure generated by the hydraulic system within $20 \mathrm{~ms}$, and the unloading 
flow rate can reach up to $1207 \mathrm{~L} / \mathrm{min}$. The above shows that the two-stage safety valve can unload the impact load of the hydraulic support column with rapid and large flow. Therefore, the two-stage safety valve has better impact resistance than the conventional safety valve.

\section{Conclusions}

In this paper, a two-stage safety valve is presented to replace the conventional safety valve used in hydraulic support. According to the structure of the valve, a mathematical model of the column circuit with the two-stage safety valve opening and closing process is established. And dynamic characteristics of the two-stage safety valve with different impact forms are studied. A rapid impact loading test rig has been built to test the two-stage safety valve under three impact pressures. In summary, the following conclusions can mainly be drawn:

- When impact duration is constant, impact speed is increased, fluctuation of the two-stage safety valve is intensified, pressure and flow fluctuation amplitude are increased, and the peak value of the pressure and flow is increased.

- When the impact speed is constant, the impact duration and pressure stable time of the two-stage safety valve are shortened, but the pressure rise time is not changed.

- The steady pressure of the two-stage safety valve is $45 \mathrm{MPa}$, steady flow is $950 \mathrm{~L} / \mathrm{min}$, pressure rise time is $20 \mathrm{~ms}$, pressure overshoot is less than $30 \%$. The two-stage safety valve has high sensitivity and good unloading performance, and it can realize fast and large flow unloading of the hydraulic support under different impact forms and pressures. The dynamic characteristics of two-stage valve can satisfy the requirements of coal mining support.

\section{Acknowledgment}

This work was supported by National Natural Science Foundation of China (grant No. 51574140), and Liaoning Provincial Natural Science Foundation of China (grant No. 20180550584).

\section{References}

1. Amirante R., Distaso E., Tamburrano P., 2016, Sliding spool design for reducing the actuation forces in direct operated proportional directional valves: Experimental validation, Energy Conversion and Management, 19, 399-410

2. Boutrid A., Duouamaa M.C., Chettibi M., Bounedja A., Talhi K., 2016, Design of a model powered support system in Kenadsa mine (Algeria), Journal of Mining Science, 10, 2, 78-86

3. Brodny J., 2010, Determining the working characteristic of a friction joint in a yielding support, Archives of Mining Sciences, 55, 4, 733-746

4. Brodny J., 2011, Tests of friction joints in mining yielding supports under dynamic load, Archives of Mining Sciences, 56, 2, 303-318

5. Dai K.Y., Xie F.W., Gao Q.S., Zhang D.S., Ding E.M., Guo X.J., 2018, Theoretical and experimental research on the pressure response characteristics of cartridge electromagnetic relief valve, International Journal of Structural Integrity, 9, 1, 65-75

6. Gao H.P., Li B.R., Yang G., 2013, Study on the influence of flow force on a large flowrate directional control valve, IFAC Proceedings Volumes, 46, 5, 469-477

7. Geary, W., 2013, Failure analysis of solenoid valve components from a hydraulic roof support, Case Studies in Engineering Failure Analysis, 3, 1, 209-216 
8. He X.F., Luo L.J., Liu X.L., Luo X.H., 2013, Simulation on an experimental system for the dynamic characteristics of safety valves with high pressure and large flow rate, Applied Mechanics and Materials, 263, 748-755

9. Lei J.B., TaO J.F., LiU C.L., Wu Y.J., 2018, Flow model and dynamic characteristics of a direct spring loaded poppet relief valve, Proceedings of the Institution of Mechanical Engineers, Part C: Journal of Mechanical Engineering Science, 232, 9, 1657-1664

10. LiaO Y.Y., Lian Z.S., Feng J.L., YuAn H.B., ZhaO R.H., 2018, Effects of multiple factors on water hammer induced by a large flow directional valve, Strojniški vestnik - Journal of Mechanical Engineering, 64, 5, 329-338

11. LiaO Y.Y., Lian, Z.S., Long R.S., Yuan H.B., 2015a, Effects of multiple factors on the stress of the electro-hydraulic directional valve used on the hydraulic roof supports, International Journal of Applied Electromagnetics and Mechanics, 47, 1, 199-209

12. LiaO Y.Y., Yuan H.B., Lian Z.S., Feng J.L, Guo Y.C., 2015b, Research and analysis of the hysteresis characteristics of a large flow directional valve, Strojniški vestnik - Journal of Mechanical Engineering, 61, 6, 355-364

13. Lisowski E., Filo G., 2016, CFD analysis of the characteristics of a proportional flow control valve with an innovative opening shape, Energy Conversion and Management, 123, 15-28

14. Lisowski E., Filo G., Rajda J., 2018, Analysis of flow forces in the initial phase of throttle gap opening in a proportional control valve, Flow Measurement and Instrumentation, 59, 3, 157-167

15. LiU W., Wei J.H., FAng J.H., Li S.Z., 2015, Hydraulic-feedback proportional valve design for construction machinery, Proceedings of the Institution of Mechanical Engineers, Part C: Journal of Mechanical Engineering Science, 229, 17, 3162-3178

16. Posa A., Oresta P., Lippolis A., 2013, Analysis of a directional hydraulic valve by a direct numerical simulation using an immersed-boundary method, Energy Conversion and Management, 65, 497-506

17. Pytlik A., 2015, Process characteristics of hydraulic legs equipped with safety valves at dynamic load caused by a mining tremor, Archives of Mining Sciences, 60, 2, 595-612

18. Szurgacz D., 2015a, Electrohydraulic control systems for powered roof supports in hazardous conditions of mining tremors, Journal of Sustainable Mining, 14, 4, 157-163

19. SzurGacz D., 2015b, Numerical analysis for an optimization of a powered roof support operating in hazard conditions of minig tremors, Mining Science, 22, 2, 171-179

20. Szurgacz D., Brodny J., 2018a, Analysis of load of a powered roof support's hydraulic leg, E3S Web of Conferences EDP Sciences, 71, 00002

21. Szurgacz D., Brodny J., 2018b, Dynamic tests of a leg in a powered roof support equipped with an innovative hydraulic system, E3S Web of Conferences EDP Sciences, 41, 03019

22. Szurgacz D., Brodny J., 2019, Analysis of the influence of dynamic load on the work parameters of a powered roof support's hydraulic leg, Sustainability, 11, 9, 2570

23. Xu B., Ding R.Q., Zhang J.H., Su Q., 2014, Modeling and dynamic characteristics analysis on a three-stage fast-response and large-flow directional valve, Energy Conversion and Management, 79, 187-199

24. Verma A.K., DeB D., 2013, Numerical analysis of an interaction between hydraulic-powered support and surrounding rock strata, International Journal of Geomechanics, 13, 2, 181-192

25. Wang F., Duan C., Tu S., Liang N., Bai Q., 2017, Hydraulic support crushed mechanism for the shallow seam mining face under the roadway pillars of room mining goaf, International Journal of Mining Science and Technology, 27, 5, 853-860

26. Yang S., Wu D.Z., Lai Z.N., Du T., 2017, Three-dimensional computational fluid dynamics simulation of valve-induced water hammer, Proceedings of the Institution of Mechanical Engineers, Part C: Journal of Mechanical Engineering Science, 231, 12, 2263-2274 
27. Zeng Q.L., Meng Z.S., Wan L.R., Wang C.L., 2018a, Analysis on force transmission characteristics of two-legged shield support under impact loading, Shock and Vibration, 10, 1-10

28. Zeng X.T., Meng G.Y., Zhou J.H., 2018b, Analysis on the pose and dynamic response of hydraulic support under dual impact loads, International Journal of Simulation Modelling, 17, 1, 69-80

29. Zhang J.L., Li D.L., Ma S.G., Wang Y.Q., Fu P.D., 2011, Dynamic characteristics analysis of high water-based large flow safety valve, Advanced Materials Research, 291, 2438-2442

30. ZhaO J.Y., LiU L.L., 2018, Influence of reversing impact load on performance of a two-step unloading pilot-operated check valves, Journal of the Brazilian Society of Mechanical Sciences and Engineering, 40, 6, 295-305

31. Zhao T., Liu C., Yetilmezsoy K., Peilin G., Yi K., Chen D., 2018, Segmental adjustment of hydraulic support setting load in hard and thick coal wall weakening: A study of numerical simulation and field measurement, Journal of Geophysics and Engineering, 15, 6, 2481-2491

Manuscript received August 9, 2019; accepted for print November 4, 2019 